\title{
The flora of the respiratory tract in chronic disease*
}

\author{
J. ROBERT MAY \\ B.A., M.D., F.C.Path. \\ Department of Bacteriology, Cardiothoracic Institute, Brompton Hospital, London
}

\begin{abstract}
Summary
Assessment of the significance of the presence or absence of pathogenic bacteria in sputum specimens is made difficult by a number of factors which are discussed. It is now generally accepted that Haemophilus influenzae is the organism most commonly responsible for recurrent or persistent sputum purulence in chronic lower respiratory disease. The close association between this organism and chronic bronchitis has been confirmed by studies of precipitin antibodies. In patients with cystic fibrosis precipitin antibodies to Pseudomonas aeruginosa and Staphylococcus aureus are frequently present: they are less commonly found in patients with bronchiectasis and very rarely in patients with chronic bronchitis.
\end{abstract}

A PROBLEM with which the clinical bacteriologist in a hospital routine laboratory is frequently confronted is the assessment of the pathogenic significance of organisms isolated from the sputum of patients with chronic respiratory disease. The difficulties are multiple. Firstly, the well known sampling errors in the search for tubercle bacilli in sputum apply equally to chronic infection by other species, notably $H$. influenzae, and consequently it is necessary not only to homogenize specimens before culture but also to examine several specimens in order to ensure that a complete picture of the patient's flora is obtained. Secondly, sputum is inevitably contaminated with pharyngeal organisms during expectoration and, since some lower respiratory pathogens, especially $H$. influenzae and the pneumococcus, are frequently found as commensals in the upper respiratory tract, their isolation from sputum does not constitute proof of lower respiratory origin. Thirdly, $H$. influenzae and pneumococci may fail to survive in sputum for more than a few hours at usual ambient temperatures and may, therefore, not be detected if the sputum is not cultured soon after expectoration. Finally, in patients who have received much chemotherapy antibiotic resistant enterobacteria or pseudomonae may colonize the respiratory tract, adding two further difficulties to interpretation of sputum culture. They may

* Paper read by the late Professor May at 'Research Work in Progress' Symposium, British Postgraduate Medical Federation, 19 February 1974. be present in such numbers that $H$. influenzae or pneumococci are overgrown or inhibited, and so remain undetected; further, their mere presence in the sputum in no way indicates that they are necessarily harmful to the patient, and decision about their significance in this context presents perhaps the biggest difficulty of all.

In spite of the difficulties of sputum culture, many studies of the correlation between sputum flora and the patient's clinical state before and after chemotherapy have indicated a general pattern of pathogenic significance of various bacterial species. In particular there is widespread acceptance of the view that $\boldsymbol{H}$. influenzae is most commonly responsible for persistent or recurrent pus in the sputum, and there is evidence that in general the enterobacteria and pseudomonae do not give rise to chronic infection in patients suffering from, say, chronic bronchitis. However, there are exceptions to every rule, and these general conclusions cannot be held to be invariably valid in the interpretation of the findings in every individual patient.

During the last few years we have studied the occurrence in chronic respiratory disease of serum precipitins against organisms found in the sputum, in the hope that detection or failure to detect such antibodies might provide positive evidence regarding the pathogenic significance of different species in individual patients. In general it has been found that, although the precipitin test has its limitations, in very many instances it has proved far more useful than sputum culture in the assessment of individuals. Further, analysis of the results of several thousand tests has drawn attention to distinct patterns of infection, from which it may be deduced that certain bacterial species are likely to be the cause of chronic infection in some clinical states but not in others.

\section{Methods}

The precipitin test is based on the Ouchterlony double-diffusion agar-gel principle. Details have been reported elsewhere (May, 1972) and it is necessary here only to comment briefly on certain aspects of it. The bacterial antigen extracts are prepared by ultrasonic disruption of organism suspensions, the final preparation containing only cytoplasmic antigens with no cell-wall material. It is unfortunate 
that this type of extract contains not only antigens specific to the relevant species but also, in the case of Gram-negative organisms, antigens which are common to a variety of species (e.g. $H$. influenzae, Pseudomonas aeruginosa, Klebsiella spp.). Hitherto, in order to distinguish between antibodies against 'specific' and 'non-specific' antigens it has been necessary first to carry out an initial screening doublediffusion test and then to retest positive sera against electrophoresed antigen extracts. It was found that the main specific antigens migrated, at $\mathrm{pH} 8 \cdot 2$, towards the cathode or failed to move from the starting point, while non-specific components migrated towards the anode. Thus, in the practical test, sera were reported as 'positive' only if, when tested by immunoelectrophoresis, they gave rise to precipitin arcs at or on the cathodal side of the point of application of the antigen extract. The whole process was somewhat cumbersome and time-consuming and has now been superseded by a simple doublediffusion test in which the antigen extract contains only species-specific antigens. It has recently been shown that such extracts can easily be prepared by absorption of non-specific components out of the crude material with DEAE-Sephadex at pH 8 (Davies, Laughton and May, 1974). In the account which follows, the occurrence only of speciesspecific precipitins will be considered.

\section{Results}

Table 1 shows the occurrence of precipitins against $H$. influenzae, $P$. aeruginosa and Klebsiella pneumoniae in the serum of normal subjects and groups of patients with chronic respiratory disease. A number of points should be noted.

1. Haemophilus precipitins were found in the serum of $8 \%$ of normal subjects. Although no information about the smoking habits of these subjects is available, recent observations suggest that this factor may have been important. May et al. (1973) demonstrated a highly specific correlation between cigarette smoking and Haemophilus precipitins, independent of correlations between smoking and mucus hypersecretion or airways obstruction. Further, Gregg (personal communication) has now demonstrated the absence of Haemophilus precipitins from the serum of clinically normal subjects who have never smoked cigarettes. Thus, it may be concluded that the detection of Haemophilus precipitins in the serum of a subject is a valid indication that tissue invasion by the organism has occurred at some time. Further, the relationship between Haemophilus precipitins and smoking suggests that $H$. influenzae is far more intimately involved in the aetiology of chronic bronchitis than has hitherto been believed.

2. Haemophilus precipitins are much more prevalent in each of the disease groups than in normal subjects, whether or not they smoke. In fact, especially in the chronic bronchitics, the figures shown in the table are misleadingly low, because no distinction has been made between patients with early disease, in whom chronic infection has not yet become established, and those with advanced disease in whom persistent infection is the rule. Haemophilus precipitins are demonstrable in the serum of about $80 \%$ of the latter group, whatever the nature of the underlying disease.

3. Precipitins against $P$. aeruginosa are not found in normal subjects and are very rare in patients suffering from chronic bronchitis, confirming the earlier belief that in this condition Pseudomonas does not cause chronic infection. In conditions characterized by more destructive lesions, however, such as bronchiectasis and especially cystic fibrosis, chronic Pseudomonas infection is common, and there is evidence that it is nowadays a frequent cause of death in cystic fibrosis (May, Herrick and Thompson, 1972). It should be emphasized that Pseudomonas precipitins are found in the serum only when the infecting strain is one with mucoid colonial morphology. The classical 'rough' strains are apparently unable to cause chronic infection of the respiratory tract, in contrast to the urinary tract.

TABLE 1. The occurrence of antibacterial precipitins in the serum of normal subjects and patients with chronic respiratory disease

\begin{tabular}{|c|c|c|c|c|}
\hline \multirow[b]{2}{*}{ Subject } & \multirow[b]{2}{*}{ No. } & \multicolumn{3}{|c|}{$\begin{array}{l}\text { Percentage of subjects with serum } \\
\text { precipitins against }\end{array}$} \\
\hline & & H. influenzae & P. aeruginosa & K. pneumoniae* \\
\hline Normal & 110 & 8 & 0 & 0 \\
\hline Chronic bronchitis & 320 & 58 & 2 & 1 \\
\hline Bronchiectasis & 279 & 53 & 10 & 5 \\
\hline Cystic fibrosis & 195 & 34 & 35 & 5 \\
\hline
\end{tabular}


4. The occurrence of chronic Klebsiella infection shows a similar pattern to that caused by Pseudomonas, with the difference that Klebsiella infections are less common. There is considerable crossreactivity between extracts of different Klebsiella species, and indeed between them and other enterobacteria, e.g. Escherichia coli, Proteus, etc., and the test for Klebsiella precipitins is by no means speciesspecific (Burns, 1968). In practice, however, precipitins are detected only when the sputum isolate is $K$. ozaenae or $K$. edwardsii, the usual respiratory pathogens (Fallon, 1973), while $K$. aerogenes, coliform bacilli and Proteus, being very rarely associated with precipitins, can be regarded as non-pathogens.

The pathogenic significance of different bacterial species in chronic respiratory infections, as indicated by the findings of precipitin tests, is summarized in Table 2. For completeness Staphylococcus aureus has been included in this table because of its frequent occurrence in cystic fibrosis, but it must be pointed out that, owing to the high prevalence of staphylococcal precipitins in normal subjects, the test has limited value in the diagnosis of chronic staphylococcal infection in individual patients. The pneumococcus has not been included in the table because all available evidence suggests that chronic pneumococcal infection is a rarity and that the importance of the organism relates solely to its capacity to cause acute infection secondarily to any chronic disorder.

TABLE 2. The pathogenic significance of bacteria in chronic respiratory infections

\begin{tabular}{lccc}
\hline \multicolumn{1}{c}{ Organism } & $\begin{array}{c}\text { Chronic } \\
\text { bronchitis }\end{array}$ & Bronchiectasis & $\begin{array}{c}\text { Cystic } \\
\text { fibrosis }\end{array}$ \\
\hline $\begin{array}{l}\text { H. influenzae } \\
\text { P. aeruginosa } \\
\text { (mucoid) }\end{array}$ & +++ & +++ & +++ \\
$\begin{array}{l}\text { P. aeruginosa } \\
\text { (non-mucoid) }\end{array}$ & - & ++ & +++ \\
K. pneumoniae* & - & - & - \\
K. aerogenes & - & + & + \\
Coliform bacilli & - & - & - \\
Proteus & - & - & - \\
Staph. aureus & - & - & - \\
\hline
\end{tabular}

\section{Discussion}

The precipitin test, then, besides giving invaluable information in the assessment of individual subjects has provided useful guidelines to the likely pathogenicity of different species in various clinical situations, and those guidelines may well be useful to bacteriologists and chest physicians on occasions when precipitin testing may not be available. Numerous questions and problems relating to the test arise, however, and it is, perhaps, pertinent to mention two here. First, the antibodies detected by the test seem to be unrelated to protective immunity against the relevant organism, since the antibodies are found most frequently in patients with the most severe infections. Secondly, whatever the infecting organism or the clinical condition, a number of apparently false-negative results have been obtained. Since the first encounter between a bacterium and the respiratory tract of the host involves contact between the bacterial cell-wall and the cells of the respiratory mucous membrane, it may be that locally produced antibody against cell-wall antigens would be more relevant to protection than the systemically produced antibody against cytoplasmic antigens which we have previously studied. Further, perhaps local anti-cell-wall antibody might provide a better index of infection than serum antibody. Considerations of this sort led to the study of antibodies in sputum to be described by $\mathrm{Dr} \mathrm{C}$. W. Clarke.

\section{References}

Burns, M.W. (1968) Precipitins to Klebsiella and other enterobacteria in the serum of patients with chronic respiratory disorders. Lancet, i, 383.

Davies, J.L., Laughton, C.R. \& May, J.R. (1974) An improved test for Haemophilus influenzae precipitins in the serum of patients with chronic respiratory disease. Journal of Clinical Pathology, 27, 265.

FALLON, R.J. (1973) The relationship between the biotype of Klebsiella species and their pathogenicity. Journal of Clinical Pathology, 26, 523.

MAY, J.R. (1972) The chemotherapy of chronic bronchitis and allied disorders. Second edition, p. 99. English Universities Press: London.

MAY, J.R., HerRick, N.C. \& Thompson, D. (1972) Bacterial infection in cystic fibrosis. Archives of Diseases in Childhood, 47, 908.

MAy, J.R., Peto, R., Tinker, C.M. \& Fletcher, C.M. (1973) A study of Haemophilus influenzae precipitins in the serum of working men in relation to smoking habits, bronchial infection and airway obstruction. American Review of Respiratory Diseases, 108, 460. 